\title{
Lower argatroban starting dose and lower aPTT goal range instead of aggressive monitoring
}

\author{
Tanja Astrid Treschan • Martin Beiderlinden
}

Published online: 11 January 2013

(C) Springer Science+Business Media New York 2013

Sir,

With great interest we read the article "Bleeding risk factors associated with argatroban therapy in the critically ill" by Doepker and colleagues in your journal[1]. The authors report on their one year experience with argatroban in 73 critically ill patients. They found a bleeding incidence of $22 \%$ and that bleeding risk was associated with major surgery, elevated bilirubin plasma levels $>3 \mathrm{mg} / \mathrm{dL}$, low platelet counts $\leq 70 \mathrm{~K} / \mu \mathrm{L}$ and initial dosing weight $>90 \mathrm{~kg}$. Doepker et al. conclude that "the results suggest that patients with these risk factors require more aggressive monitoring".

We disagree with this conclusion. We have recently shown, that an argatroban starting dose of $0.2 \mu \mathrm{g} / \mathrm{kg} \mathrm{min}{ }^{-1}$ is sufficient and safe for effective anticoagulation in critically ill patients, when the goal aPTT is 1.5-2 times baseline [2]. Doepker et al. used initial argatroban doses of $0.45 \pm 25 \mu \mathrm{g} / \mathrm{kg} \mathrm{min}^{-1}$ for patients with bleeding events and $0.56 \pm 0.37 \mu \mathrm{g} / \mathrm{kg} \mathrm{min}^{-1}$ for patients without bleeding. In contrast, they report steady state doses of $0.41 \pm 28$ and $0.34 \pm 25 \mu \mathrm{g} / \mathrm{kg} \mathrm{min}{ }^{-1}$ for patients with and without bleeding, respectively. Thus, steady state doses were equal to or, in patients without bleeding considerably lower, than starting doses. This is remarkable because in $63 \%$ of patients with bleeding events, aPTT goal range was $2-2.5 \times$ baseline although $75 \%$ of them had major surgery. The higher aPTT goal range in these patients contrasts the methods section, where the authors state "that in patients considered to be at a high risk of bleeding (e.g. recent major surgery) "goal aPTT was 1.5-2 times".

Based on the unfortunate combination of risk factors and aPTT goal range in patients with bleeding, we believe the results presented by Doepker et al. warrant two different conclusions: (1) Patients with risk factors should receive lower argatroban starting doses and (2) aPTT goal range should be 1.5-2 times baseline in patients with risk factors, if no thrombo-embolic complications are detected at the time of HIT suspicion.

\section{References}

1. Doepker B, Mount KL, Ryder LJ, Gerlach AT, Murphy CV, Philips GS (2012) Bleeding risk factors associated with argatroban therapy in the critically ill. J Thromb Thrombolysis 34(4):491-498

2. Beiderlinden M, Treschan TA, Görlinger K, Peters J (2007) Argatroban anticoagulation in critically ill patients. Ann Pharmacother 41(5):749-754
T. A. Treschan $(\bowtie) \cdot$ M. Beiderlinden

KLiPS Department of Anesthesiology, Düsseldorf University

Hospital, Moorenstr. 5, 40225 Düsseldorf, Germany

e-mail: tanja.treschan@med.uni-duesseldorf.de 